\title{
Editorial: Early Genetic and Clinical Diagnosis in MEN1
}

\author{
Delmar M. Lourenço Jr. ${ }^{1,2 \star}$ and Wouter W. de Herder ${ }^{3}$ \\ ${ }^{1}$ Endocrine Genetics Unit (LIM-25), Endocrinology Division, Hospital das Clínicas, University of São Paulo School of \\ Medicine, São Paulo, Brazil, ${ }^{2}$ Endocrine Oncology Division, Institute of Cancer of the State of São Paulo, São Paulo, Brazil, \\ ${ }^{3}$ Sector Endocrinology, Department of Internal Medicine, ENETS Centre of Excellence, Erasmus MC Cancer Institute, \\ Erasmus MC - University Medical Center, Rotterdam, Netherlands
}

Keywords: multiple endocrine neoplasia type 1, MEN1 gene, early diagnosis, screening, young, adolescent

\section{Editorial on the Research Topic}

\section{Early Genetic and Clinical Diagnosis in MEN1}

Multiple endocrine neoplasia type 1 (MEN1, OMIM 131100) is an autosomal dominant inherited syndrome caused by germline mutations in the MEN1 gene that predisposes carriers to variable risk of development of tumors in diverse non-endocrine and endocrine organs. The main MEN1-related endocrine tumors affect the parathyroid and pituitary glands, pancreatic islets and duodenal endocrine cells. Most MEN1 carriers develop main tumors between 5 and 80 years with at least one them initiating around 20-30 years (50-60\%) and, invariably, 94\% of MEN1 carriers have developed one or more disease manifestations at the age of 50 years. MEN1 is associated with decreased life expectancy, which in $75 \%$ of patients is caused by disorder-related morbidity/mortality (1). Different clinical protocols have been recommended to allow the early diagnosis and treatment of MEN1-related tumors in MEN1 mutation carriers (1-7). Although

OPEN ACCESS

Edited and reviewed by: Antonino Belfiore,

University of Catania, Italy

*Correspondence:

Delmar M. Lourenço Jr. delmarmuniz@usp.br;

delmar.muniz@hc.fm.usp.br; delmarmuniz@hotmail.com

Specialty section:

This article was submitted to Cancer Endocrinology, a section of the journal Frontiers in Endocrinology

Received: 17 February 2020 Accepted: 26 March 2020 Published: 15 April 2020

Citation:

Lourenço DM Jr and de Herder WW (2020) Editorial: Early Genetic and Clinical Diagnosis in MEN1.

Front. Endocrinol. 11:218 doi: 10.3389/fendo.2020.00218 the Clinical Practice Guidelines for MEN1 has recommended periodic vigilance initiating at 5, 8, and 10 years of age (1), respectively, for pituitary adenoma, primary hyperparathyroidism (HPT) and neuroendocrine pancreatic tumors, there are only a few papers emphasizing clinical features, management and treatment of children and adolescents with MEN1 (3, 8-13).

In the present issue of the Frontiers in Endocrinology, this topic was widely discussed by two independent research groups (Kamilaris and Stratakis; de Laat et al.). Kamilaris and Stratakis presented an updated and complete review on the genetics and molecular pathogenesis, including indications for performing the MEN1 mutational analysis, diagnosis and treatment of the main MEN1-related tumors in young patients. These authors revisited a number of papers addressing the occurrence of these tumors at young ages, reinforcing the importance and the pivotal role of periodic biochemical and radiological surveillance of MEN1 carriers (Kamilaris and Stratakis).

The DutchMEN group critically debated the current clinical diagnosis of MEN1, emphasizing the different outcomes of true MEN1 cases harboring MEN1 mutations and phenocopies. The latter group is defined as, (i) MEN1-like phenotypes harboring germline mutations in other genes (AIP or CDKIs genes), and (ii) mutation-negative cases secondary to sporadic and casual cooccurrence of two MEN1 tumors (de Laat et al.). Also, these authors suggested less strict strategies of vigilance for phenocopies. In addition, de Laat et al. reported that a scenario of late MEN1 diagnosis involving MEN1 index cases and family members is yet highly prevalent in developed countries. Importantly, both the low rate of clinical suspicion of MEN1 by clinicians and the delayed genetic testing of family members of MEN1 patients were associated with higher morbidity and mortality. The prompt recognition of suspected clinical features by clinicians, accessible genetic testing, centralization and monitoring of MEN1 care through national registries were useful in Netherlands to diagnose MEN1 earlier (de Laat et al.). 
As mentioned, the study of MEN1 in children and adolescents is still limited. Recently, Marx and Lourenço debated diverse questions and controversies on HPT occurring in young MEN1 carriers as parathyroid pathophysiology, the differential diagnosis of HPT with other hypercalcemic genetic disorders, the importance of periodic vigilance and early diagnosis, criteria to indicate early parathyroid surgery and different treatment strategies (Marx and Lourenço). This debate gains strength due to the complete penetrance of HPT in MEN1, the high occurrence of this tumor as the first clinical manifestation and the frequent presence of HPT in adolescent and young adult MEN1 patients.

Also, the clinical and surgical experience of the Italian group in the follow-up and surgery of youngers with MEN1-related HPT has been recently reported (Marini et al.). These authors described 19 young MEN1 cases diagnosed with HPT before $20 \mathrm{y}$, the surgical strategies adopted and discussed critically the risks and benefits of early parathyroidectomy (PTX) in MEN1, since the ideal timing to indicate PTX in such cases is still not known (Marini et al.). The same group, in a retrospective study, emphasized the efficacy reached by the total PTX (TPTX) approach followed by parathyroid autotransplantation in 28 out of $38 \mathrm{HPT} / \mathrm{MEN} 1$ patients diagnosed before the age of $30 \mathrm{y}$, in comparison with nine other similar patients submitted to subtotal parathyroidectomy (SPTX) (Tonelli et al.). In the long-term follow up (11.8 $\pm 6.6 \mathrm{y}$ ), relatively low rates of recurrence ( 14 vs. $22 \%$ ) were observed when patients were submitted, respectively, to either TPTX and SPTX, whereas the rate of permanent hypoparathyroidism was 17.9 vs. $22 \%$, respectively (Tonelli et al.). In addition, early demineralization was documented in two young MEN1 cases with HPT, followed by recovery of bone mineral density (BMD) after PTX (Tonelli et al.). These data reinforced previous findings documenting both the early bone loss in young HPT/MEN1 cases and the positive impact of PTX on bone health, leading to a significant BMD increase 12 months after surgery (14-19).

Recently, a protocol applied to HPT/MEN1 patients followed up by the MD Anderson Cancer Center was reported including preoperative evaluation, intraoperative decision-making as to initial cases and reoperations, and the step by step SPTX procedures, elected as the preferential surgical approach (Nobecourt et al.). In 2019, a large Brazilian cohort of 161 HPT/MEN1 patients submitted to PTX between 1987 and 2018 was reported (Montenegro et al.). Among them, 94 patients (58.4\%) were operated on between 2011 and 2018 including seven out of nine patients younger than $21 \mathrm{y}$ (Montenegro et al.). These findings might suggest a tendency to a recent increase in the number of HPT/MEN1 adolescents submitted to PTX and they are most probably due to more accessible genetic testing and active periodic vigilance of MEN1 carriers, contrasting with previous periods (20-22). Furthermore, based on four adolescent HPT/MEN1 cases that underwent unintentional less than SPTX, Montenegro et al. debated on the potential risks and benefits of less extensive PTX procedures applied to the specific subset of young HPT/MEN1 patients presenting a documented localized disease. The need for more extensive studies on this specific topic was stressed (Montenegro et al.).

In fact, some groups have reported experiences with less extensive parathyroid surgeries in MEN1, independent of age (23-27). These protocols might potentially minimize the risks of hypoparathyroidism in younger MEN1 patients in which peak bone mass was not yet reached. In contrast, less extensive PTX procedures would increase the risks of surgical failure, which may lead to persistent or early recurrent HPT. However, classical surgical protocols as mostly SPTX, and also TPTX, remain elective surgeries for MEN1 patients whereas more studies are necessary to validate the efficacy of less extensive surgeries in young MEN1 cases with HPT (Tonelli et al.; Nobecourt et al.; Montenegro et al.) (28-36).

Recently, Dantas et al. described a young MEN1 patient presenting hydrocephalus and intracranial hypertension caused by a giant prolactinoma as first clinical manifestations of MEN1. The importance of refining and reaching a more effective periodic screening program to avoid acute lifethreatening events was mentioned. Also, an extensive review on giant prolactinoma occurring as part of MEN1 was offered (Dantas et al.).

Conversely, two research groups from Italy and Brazil collaborated in this topic in Frontiers in Endocrinology amplifying the strict spectrum of original studies on MEN1-related tumors occurring at young ages suggesting potential peculiarities of the management and treatment of such cases (Marini et al.; Tonelli et al.; Montenegro et al.; Dantas et al.). However, due to the rarity of this disorder and the few studies focusing on a large number of affected young MEN1 carriers, is not surprising the adoption of divergent protocols of management and treatment by different expert groups. These data indicate that more studies should be warranted to optimize strategies of follow-up, attempting to reach more secure and effective decision-making concerning treatment of the young patients with MEN1 syndrome.

Thus, overall, the papers of Kamilaris and Stratakis, de Laat et al., Marx and Lourenço, Nobecourt et al. updated, commented and transmitted important experiences attempting to amplify our knowledge on the present Research Topic in Frontiers in Endocrinology.

\section{AUTHOR CONTRIBUTIONS}

DL concepted, designed, and wrote the editorial. WH collaborated with improvements to the editorial writing.

\section{FUNDING}

DL has been supported by FAPESP grants (2013/19810-2; 2015/25444-4; 2016/07504-2). 


\section{REFERENCES}

1. Thakker RV, Newey PJ, Walls GV, Bilezikian J, Dralle H, Ebeling PR, et al. Clinical practice guidelines for multiple endocrine neoplasia type 1 (MEN1). $J$ Clin Endocrinol Metab. (2012) 97:2990-11. doi: 10.1210/jc.2012-1230

2. Brandi ML, Gagel RF, Angeli A, Bilezikian JP, Beck-Peccoz P, Bordi C, et al. Guidelines for diagnosis and therapy of MEN type 1 and type 2. J Clin Endocrinol Metab. (2001) 86:5658-71. doi: 10.1210/jcem.86.12.8070

3. Lairmore TC, Piersall LD, DeBenedetti MK, Dilley WG, Mutch MG, Whelan AJ, et al. clinical genetic testing and early surgical intervention in patients with Multiple Endocrine Neoplasia Type 1 (MEN 1). Ann Surg. (2004) 239:637-45; discussion 645-7. doi: 10.1097/010000124383.sla.98416.8d

4. Lourenço DM Jr, Toledo RA, Coutinho FL, Margarido LC, Siqueira SA, dos Santos MA, et al. The impact of clinical and genetic screenings on the management of the multiple endocrine neoplasia type 1. Clinics. (2007) 62:465-76. doi: 10.1590/S1807-59322007000400014

5. Waldmann J, Fendrich V, Habbe N, Bartsch DK, Slater EP, Kann PH, et al. Screening of Patients with Multiple Endocrine Neoplasia Type 1 (MEN-1): a critical analysis of its value. World J Surg. (2009) 33:1208-18. doi: 10.1007/s00268-009-9983-8

6. Pieterman CR, Vriens MR, Dreijerink KM, van der Luijt RB, Valk GD. Care for patients with multiple endocrine neoplasia type 1: the current evidence base. Fam Cancer. (2011) 10:157-71. doi: 10.1007/s10689-010-9398-6

7. Marini F, Giusti F, Tonelli F, Brandi ML. Management impact: effects on quality of life and prognosis in MEN1. Endoc Relat Cancer. (2017) 24:T227-42. doi: 10.1530/ERC-17-0203

8. Stratakis CA, Schussheim DH, Freedman SM, Keil MF, Pack SD, Agarwal SK, et al. Pituitary macroadenoma in a 5-year-old: an early expression of multiple endocrine neoplasia type 1. J Clin Endocrinol Metab. (2000) 85:4776-80. doi: 10.1210/jcem.85.12.7064

9. Oiwa A, Sakurai A, Sato Y, Sakuma T, Yamashita K, Katai M, et al. Pituitary adenomas in adolescent patients with Multiple Endocrine Neoplasia Type 1. Endocr J. (2002) 49:635-40. doi: 10.1507/endocrj.49.635

10. Newey PJ, Jeyabalan J, Walls GV, Christie PT, Gleeson FV, Gould S, et al. Asymptomatic children with multiple endocrine Neoplasia type 1 mutations may harbor nonfunctioning pancreatic neuroendocrine tumors. $J$ Clin Endocrinol Metab. (2009) 94:3640-46. doi: 10.1210/jc.2009-0564

11. Gonçalves TD, Toledo RA, Sekiya T, Matuguma SE, Maluf Filho F, Rocha MS, et al. Penetrance of functioning and nonfunctioning pancreatic neuroendocrine tumors in multiple endocrine neoplasia Type 1 in the second decade of life. J Clin Endocrinol Metab. (2014) 99:E89-96. doi: 10.1210/jc.2013-1768

12. Goudet P, Dalac A, LeBras M, Cardot-Bauters C, Niccoli P, Lévy-Bobbot N, et al. MEN1 disease occurring before 21 years old: a 160-patient cohort study from the Group d'étude des Tumeurs Endocrines. J Clin Endocrinol Metab. (2015) 100:1568-77. doi: 10.1210/jc.2014-3659

13. Vannucci L, Marini F, Giusti F, Ciuffi S, Tonelli F, Brandi ML. MEN1 in children and adolescents: data from patients of a regional referral center for hereditary endocrine tumors. Endocrine. (2018) 59:438-48. doi: 10.1007/s12020-017-1322-5

14. Burgess JR, David R, Greenaway TM, Parameswaran V, Shepherd JJ. Osteoporosis in multiple endocrine neoplasia type 1: severity, clinical significance, relationship to primary hyperparathyroidism, and response to parathyroidectomy. Arch Surg. (1999) 134:1119-23. doi: 10.1001/archsurg. 134.10 .1119

15. Lourenço DM Jr, Toledo RA, Mackowiak II, Coutinho FL, Cavalcanti MG, Correia-Deur JE, et al. Multiple endocrine neoplasia type 1 in Brazil: MEN1 founding mutation, clinical features, and bone mineral density profile. Eur J Endocrinol. (2008) 159:259-74. doi: 10.1530/EJE-0 8-0153

16. Lourenço DM Jr, Coutinho FL, Toledo RA, Montenegro FL, Correia-Deur JE, Toledo SP. Early-onset, progressive, frequent, extensive, and severe bone mineral and renal complications in multiple endocrine neoplasia type lassociated primary hyperparathyroidism. J Bone Miner Res. (2010) 25:238291. doi: 10.1002/jbmr.125

17. Lourenço DM Jr, Coutinho FL, Toledo RA, Gonçalves TD, Montenegro FL, Toledo SP. Biochemical, bone and renal patterns in hyperparathyroidism associated with multiple endocrine neoplasia type 1. Clinics. (2012) 67 (Suppl. 1):99-108. doi: 10.6061/clinics/2012(sup01)17

18. Coutinho, FL, Lourenço DM Jr, Toledo RA, Montenegro FL, CorreiaDeur, et al. Bone mineral density analysis in patients with primary hyperparathyroidism associated with multiple endocrine neoplasia type 1 after total parathyroidectomy. Clin Endocrinol. (2010) 72:462-8. doi: $10.1111 / j .1365-2265.2009 .03672 . x$

19. Coutinho FL, Lourenco DM Jr, Toledo RA, Montenegro FL, Toledo SP Post-surgical follow-up of primary hyperparathyroidism associated with multiple endocrine neoplasia type 1. Clinics. (2012) 67 (Suppl. 1):169-72. doi: 10.6061/clinics/2012(sup01)28

20. Toledo RA, Lourenço DM Jr, Coutinho FL, Quedas E, Mackowiack I, Machado MC, et al. Novel MEN1 germline mutations in Brazilian families with multiple endocrine neoplasia type 1. Clin Endocrinol. (2007) 67:377-84. doi: 10.1111/j.1365-2265.2007.02895.x

21. Toledo RA, Sekiya T, Longuini VC, Coutinho FL, Lourenço DM Jr, Toledo SP. Narrowing the gap of personalized medicine in emerging countries: the case of multiple endocrine neoplasias in Brazil. Clinics. (2012) 67 (Suppl. 1):3-6. doi: 10.6061/clinics/2012(sup01)02

22. Carvalho RA, Urtremari B, Jorge AAL, Santana LS, Quedas EPS, Sekiya T, et al. Germline mutation landscape of multiple endocrine neoplasia type 1 using full gene next-generation sequencing. Eur J Endocrinol. (2018) 179:391-407. doi: 10.1530/EJE-18-0430

23. Arnalsteen LC, Alesina PF, Quiereux JL, Farrel SG, Patton FN, Carnaille $B$, et al. Long-term results of less than total parathyroidectomy for hyperparathyroidism in multiple endocrine neoplasia type 1. Surgery. (2002) 132:1119-25. doi: $10.1067 /$ msy.2002.128607

24. Lee CH, Tseng LM, Chen JY, Hsiao HY, Yang AH. Primary hyperparathyroidism in multiple endocrine neoplasia type 1: individualized management with low recurrence rates. Ann Surg Oncol. (2006) 13:103-9. doi: 10.1245/ASO.2006.12.009

25. Versnick M, Popadich A, Sidhu S, Sywak M, Robinson B, Delbridge L. Minimally invasive parathyroidectomy provides a conservative surgical option for multiple endocrine neoplasia type 1-primary hyperparathyroidism. Surgery. (2013) 154:101-5. doi: 10.1016/j.surg.2013.03.004

26. Kluijfhout WP, Beninato T, Drake FT, Vriens MR, Gosnell J, Shen WT, et al. Unilateral clearance for primary hyperparathyroidism in selected patients with multiple endocrine neoplasia type 1. World J Surg. (2016) 40:2964-9. doi: 10.1007/s00268-016-3624-9

27. Horiuchi K, Sakurai M, Haniu K, Nagai E, Tokumitsu H, Yoshida Y, et al. Impact of "tailored" parathyroidectomy for treatment of primary hyperparathyroidism in patients with multiple endocrine neoplasia type 1. World J Surg. (2017) 42:1772-8. doi: 10.1007/s00268-017-4366-z

28. van Leeuwaarde RS, Pieterman CRC, Bleiker EMA, Dekkers OM, van der Horst-Schrivers AN, Hermus AR, et al. High fear of disease occurrence is associated with low quality of life in patients with Multiple Endocrine Neoplasia type 1 (MEN1): Results from the Dutch MEN1 Study Group. J Clin Endocrinol Metab. (2018) 103:2354-61. doi: 10.1210/jc.2018-00259

29. Giusti F, Cianferotti L, Boaretto F, Cetani F, Cioppi F, Colao A, et al. Multiple endocrine neoplasia syndrome type 1: institution, management, and data analysis of a nationwide multicenter patient database. Endocrine. (2017) 58:349-59. doi: 10.1007/s12020-017-1234-4

30. Tonelli F, Marcucci T, Fratini G, Tommasi MS, Falchetti A, Brandi ML. Is total parathyroidectomy the treatment of choice for hyperparathyroidism in multiple endocrine neoplasia type 1? Ann Surg. (2007) 246:1075-82. doi: 10.1097/SLA.0b013e31811f4467

31. Tonelli F, Giudici F, Cavalli T, Brandi ML. Surgical approach in patients with hyperparathyroidism in multiple endocrine neoplasia type 1: total versus partial parathyroidectomy. Clinics. (2012) 67:155-60. doi: 10.6061/clinics/2012(Sup01)26

32. Montenegro FLM, Lourenço DM Jr, Tavares MR, Arap SS, Nascimento CP Jr, Massoni Neto LM, et al. Total parathyroidectomy in a large cohort of cases with hyperparathyroidism associated with multiple endocrine neoplasia type 1: experience from a single academic center. Clinics. (2012) 67:131-9. doi: 10.6061/clinics/2012(Sup01)22

33. Hubbard JG, Sebag F, Maweja S, Henry JF. Subtotal parathyroidectomy as an adequate treatment for primary hyperparathyroidism in multiple endocrine 
neoplasia type 1. Arch Surg. (2006) 141:235-9. doi: 10.1001/archsurg.14 1.3.235

34. Pieterman CR, van Hulsteijn LT, den Heijer $M$, van der Luijt RB, Bonenkamp JJ, Hermus AR, et al. Primary hyperparathyroidism in MEN1 patients: a cohort study with long term follow-up on preferred surgical procedure and the relation with genotype. Ann Surg. (2012) 255:1171-8. doi: 10.1097/SLA.0b013e31824c514

35. Lairmore TC, Govendik CM, Quinn CE, Sigmond BR, Lee CY, Jupiter DC. A randomized, prospective trial of operative treatments for hyperparathyroidism in patients with multiple endocrine neoplasia type 1. Surgery. (2014) 156:1326-35. doi: 10.1016/j.surg.2014. 08.006

36. Nilubol N, Weinstein L, Simonds WF, Jensen RT, Marx SJ, Kebebew E. Limited parathyroidectomy in multiple endocrine neoplasia type 1-associated primary hyperparathyroidism: a set-up for failure. Ann Surg Oncol. (2016) 23:416-23. doi: 10.1245/s10434-015-4865-9

Conflict of Interest: The authors declare that the research was conducted in the absence of any commercial or financial relationships that could be construed as a potential conflict of interest.

Copyright (C) 2020 Lourenço and de Herder. This is an open-access article distributed under the terms of the Creative Commons Attribution License (CC BY). The use, distribution or reproduction in other forums is permitted, provided the original author(s) and the copyright owner(s) are credited and that the original publication in this journal is cited, in accordance with accepted academic practice. No use, distribution or reproduction is permitted which does not comply with these terms. 